\title{
Identifying and Meeting the Needs of Extension's Target Audiences ${ }^{1}$
}

\author{
Laura A. Warner, Glenn D. Israel, and John M. Diaz ${ }^{2}$
}

\section{Abstract}

This document provides an overview of the concept of target audiences as related to Extension education and briefly presents concepts of audience analysis and educational content selection. In contrast to the general population, a target audience is comprised of people who can take some explicit action to help solve an identified problem addressed by an Extension program. Additionally, a target audience is sometimes the people who are affected most by that problem. An understanding of the concept of target audiences paired with intentional selection of appropriate educational activities and content can support an impactful Extension program.

\section{Purpose}

This publication serves as a basic overview of this concept and a resource for participants in the UF/IFAS Program Planning and Evaluation Professional Certificate program (learn more here: https://aec.ifas.ufl.edu/e-learning/ certificates/program-planning-evaluation/). Extension professionals who are comfortable with this topic may wish to also consult Improving Extension Program Development Using Audience Segmentation (http://edis.ifas.ufl.edu/ wc188).

\section{Target Audiences}

At first glance, the questions of whom to deliver your Extension program to and what information to share seem almost too simple. However, making sure you are delivering the right message to the right people determines how successful you will be at addressing a problem through your planned Extension program.

When planning a program, an Extension professional conducts a needs assessment and links it with their target audience (Boone, Safrit, \& Jones, 2002). Theories of communication inform us that information spreads more quickly and new behaviors are adopted more readily in groups in which people are very similar (Rogers, 2003). It is important to recognize that Extension clientele are comprised of diverse people who may be differentiated into smaller groups that allow for more meaningful and impactful programming. These smaller groups should ideally share similarities pertaining to the problem you are working to solve.

Example: an Extension professional working to address the spread of invasive aquatic plants in a local lake might find boaters who use the lake to be an important target audience because they may contribute to the problem if they do not clean their boats properly, meaning they can play a role in solving the problem. Additionally, the boaters who use the

1. This document is AEC673, one of a series of the Department of Agricultural Education and Communication, UF/IFAS Extension. Original publication date May 2019. Visit the EDIS website at https://edis.ifas.ufl.edu for the currently supported version of this publication.

2. Laura A. Warner, assistant professor; Glenn D. Israel, professor; and John M. Diaz, assistant professor, Department of Agricultural Education and Communication; UF/IFAS Extension, Gainesville, FL 32611.

The Institute of Food and Agricultural Sciences (IFAS) is an Equal Opportunity Institution authorized to provide research, educational information and other services

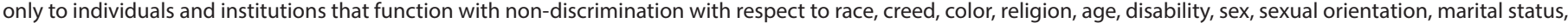

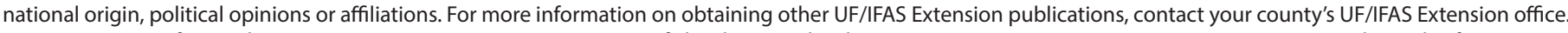
U.S. Department of Agriculture, UF/IFAS Extension Service, University of Florida, IFAS, Florida A \& M University Cooperative Extension Program, and Boards of County Commissioners Cooperating. Nick T. Place, dean for UF/IFAS Extension. 
lake might disproportionally suffer from the problem (i.e., the spread of invasive aquatic plants) compared to other local residents who do not use the lake.

Once you identify the needs your program will address, your responsibility is to identify who needs to play a part in reaching your goals. Not everyone will be in a position to act on a particular problem, and resources are not typically so abundant that Extension organizations can afford to reach everyone in a given location.

A target audience:

- Is some part of the population that has the opportunity to take some action or otherwise influence the problem you are working to solve

- Is the group of people whose needs you are trying to meet

- Is possibly, but not always, the people most affected by the problem

- Can change over time and with the evolution of a program, and should be revisited regularly

Some examples of target audiences within some Extension focus areas include:

- Small farmers who grow a particular crop in Northeast Florida (Agriculture)

- Youth ages 5-8 in Sarasota county $(4-\mathrm{H})$

- Adults with diabetes in Alachua county (FCS)

- Commercial landscape professionals in Broward county (Horticulture)

\section{Targeting}

Targeting is defined as customizing the design and delivery of a program based on the characteristics and interests of an intended audience. We can learn about those characteristics through target audience analysis (explained below).

Different target audiences will have different preferences and needs that can be identified through target audience analysis and used to inform the development of educational strategies.

The priority you give to specific audiences is determined by your area of focus as well as your organization's objectives. For example, UF/IFAS Extension professionals follow the organization's road map (UF/IFAS, 2012) to help establish their major objectives and decide how to direct their efforts. Some considerations for prioritizing different audiences include:
- Your organization's mission and goals

- The resources that are available to serve the community

- Whether certain audiences are more relevant to the organization's mission

- Legislative mandates that may require prioritization of certain audiences

- Your assigned focus and area of expertise

\section{Secondary Target Audiences}

In addition to a primary target audience-or the main audience you are trying to impact, if you have secondary target audiences-are groups that benefit indirectly from your programming. One example comes from $4-\mathrm{H}$ programming. $4-\mathrm{H}$ takes into consideration the fact that children take what they learn home to their families. The family represents a secondary audience that not only may benefit from the program but also has influence on the child's participation in 4-H. On the other hand, a public policy education program may have a primary audience of public officials or community leaders while the main beneficiaries might be farmers or families.

\section{Using Target Audience Analysis to Guide Extension Activities}

When a target audience has been identified, it is important to conduct an audience analysis to determine the audience's needs and identify ways to best serve them. Target audience analyses help Extension professionals ensure programming meets actual needs (versus assumed); is relevant, useful, and appropriate; and is received positively. A benefit to conducting audience analysis is its potential for increasing a program's effectiveness by providing the appropriate help a target audience needs to take meaningful action on a problem.

Some of the characteristics we may want to know about the target audience include:

- demographic information such as age, gender and ethnicity, primary language spoken or written, housing status, geographic location, access to resources

- educational needs and learning preferences

- family/social responsibilities

- interests and hobbies

- groups they belong to

- problems they want to solve 
- current behaviors related to the goals

- barriers to adopting certain behaviors that can help solve the problem you're working on

- whether they are aware of the problem and actions they can take to solve it, if they are thinking about taking or preparing to take that action, or even if they have begun to take action (Warner, Galindo-Gonzalez, \& Gutter, 2017)

- perceptions of the action you want them to take, such as whether they can see it in practice, if it is too complex, better than what they have done in the past, compatible with their life and values, or something they can test before committing to (Harder, 2015; Rogers, 2003)

Audience analysis activities may be conducted by accessing existing data sources, while some information may be collected directly from the audience. Some of the available existing data sources include:

- technical reports (such as those from government agencies, planning and policy documents)

- past needs assessments you or others have conducted in your local community

- program records

- attendance sheets

- meeting minutes

- requests for information

- newspaper clippings

- emails

New information can be collected in many ways such as:

- observation of the target audience

- public forums

- consultations with an Extension advisory board

- new program evaluation efforts

- interviews

- focus groups

- surveys

Taking the above identified information into consideration, the Extension professional can then design a collection of learning opportunities tailored for the target audience. An impactful Extension program is one that meets the real needs of the audience. It should solve problems they want to solve and be available in a time, place, and format that makes participation easy and enjoyable. The content design should also take into consideration audience perceptions (i.e., the topic area is perceived as being too complex or perhaps it is seen as having distinct benefits) as well as where the audience members are in terms of change (i.e., unaware, considering it, preparing to take action). Teaching methods can be drawn from a variety of hands-on, practice-based, experiential, integrative, and review activities (Stofer, 2017).

Example, continued: Returning to our example on the spread of invasive aquatic plants in a local lake, an Extension professional could examine meeting minutes from local organizations and existing information available for boaters. Reviewing this existing information might reveal potential partners in reaching the audience and help the Extension professional to learn about other issues local boaters care about and processes related to boating (such as trailer registration and parking procedures). Observation and short interviews at the local boat ramp could provide insight into what is preventing boaters from cleaning their boats properly (lack of information or other barriers) and the extent of the problem. The Extension professional might then conduct a large-scale mail or telephone survey to identify values and educational preferences among the local boating community in order to guide a large-scale educational campaign.

\section{Conclusion}

The ability to tailor Extension programs is predicated on understanding the target audience. All Extension professionals need to thoughtfully select target audiences as well as communicate who these groups are and why they are important. The target audience is the people you go to, because they have the opportunity to play a role in addressing the needs you have identified at a time and place convenient for them. Audience analysis is a useful process for identifying and deeply understanding the target audience and places the Extension professional in a position to make an impact on important problems.

\section{References}

Boone, E. J., R. D. Safrit, and L. Jones. (2002). Developing programs in adult education: A conceptual programming model (2nd ed.). Long Grove, IL: Waveland Press.

Donaldson, J. L. (n.d.). The Tennessee Extension Program Planning and Evaluation Model https://ag.tennessee.edu/ alec/Documents/PlanningEvaluation/TennesseeLogicModelExplanations.pdf 
Harder, A. (2015). Planned behavior change: An overview of the diffusion of innovations (2nd ed.). WC089. Gainesville: University of Florida Institute of Food and Agricultural Sciences. Retrieved from http://edis.ifas.ufl.edu/wc089

Monaghan, P., L. Warner, R. Telg, and T. Irani. (2014). Improving extension program development using audience segmentation. AEC526. Gainesville: University of Florida Institute of Food and Agricultural Sciences. Retrieved from http://edis.ifas.ufl.edu/wc188

Rogers, E. M. (2003). Diffusion of innovations (5th ed.). New York, NY: Free Press.

Stofer, K. A., (2017). Education and facilitation methods for Extension. AEC619. Gainesville: University of Florida Institute of Food and Agricultural Sciences. Retrieved from https://edis.ifas.ufl.edu/wc281

Swanson, B. E., R. P. Bentz, and A. J. Sofranko. (1997). Improving agricultural extension: A reference manual. Rome, Italy: Food and Agriculture Organization of the United Nations. Retrieved from: http://www.fao.org/docrep/W5830E/ w5830e00.htm\#Contents

UF/IFAS. (2012). Florida Extension Roadmap 2013 - 2023. Gainesville, FL: UF/IFAS Extension Administration. Retrieved from https://extadmin.ifas.ufl.edu/organization/ extension-roadmap/

Warner, L. A., S. Galindo-Gonzalez, and M. S. Gutter. (2017). Building impactful extension programs by understanding how people change (2nd ed.). AEC527. Gainesville: University of Florida Institute of Food and Agricultural Sciences. Retrieved from http://edis.ifas.ufl.edu/wc189 